\title{
Role of Chain Inverter to Enhance Power Quality
}

\author{
${ }^{1}$ S. Gowri Sankar Korla, ${ }^{2}$ Kumar Abhishek, ${ }^{3}$ Ashutosh Pandey \\ ${ }^{1}$ (HOD, EEE, Dr. MǴR Educational And Research Institute, India) \\ 2, ${ }_{\text {(Final Year Students, EEE, Dr. MGR Educational And Research Institute, India) }}$
}

\begin{abstract}
In this paper, a new method of minimizing the input current total harmonic distortion (THD) as well as power factor by using a chain inverter to replace a traditional inverter is presented. This proposal is verified through simulation which uses one type of DC to AC converter with 3-links which can be used to generate seven level output voltage by connecting a number of similar Insulated Gate Bipolar junctions Transistor (IGBT) in series, to form a high Voltage- Source-Inverter (VSI). The main feature of this topology is low cost, small size, high efficiency and simplicity, and is excellent for existing ac drives, UPS etc. A new method of implementing stepped voltage waveform proposed here is based on the operation principle of Chain link converter. With reference to the control algorithm, this strategy has realized for seven-level inverter which generates high quality sinusoidal voltage contains lower THD. During one cycle, each IGBT of a CLI switches 'ON/OFF' for a certain time and period using a Sinusoidal Pulse Width Modulation (SPWM) technique. This SPWM technique uses two triangular carrier bands - one positive and one negative - per link, and has a carrier frequency of twice the fundamental frequency and one modulating signal for all links. Simulation is carried out by using MATLAB/SIMULINK which confirms the feasibility of the proposed system.
\end{abstract}

Keywords: Chain Link Converter, Sinusoidal Pulse Width Modulation, VAR,SVC.

\section{Introduction}

In today's world, power supplies are extensively used inside most of electrical and electronic appliances such as in computers, monitors, televisions, audio sets and others. The high power non linear loads such as static power converter, arc furnace, adjustable speed drives etc and low power loads such as fax machine, computer, etc produce voltage fluctuations, harmonic currents and an imbalance in network system which results into low power factor operation of the power system and which is compensated by static VAR compensators (SVC). There are two techniques for controlling the converter circuit which are voltage control and PWM control. In voltage control method chopper circuit is used for varying the DC source voltage. It has several drawbacks such as high harmonics content and low power factor. Pulse Width Modulation has better performance against voltage control technique. Besides eliminating the drawbacks of voltage control technique, the circuit is also simple and less unwieldy. There are several PWM techniques that can be categorized such as MPWM, SPWM, and etc. The number of pulses and the size of pulse in each duty cycle are the criteria that are being investigated in PWM technique to eliminate the harmonic contents. On the other hand, the PWM techniques used today to control modern static converters such as machine drives, power factor compensators or active power filters, do not give smooth sinusoidal voltage shapes, which strongly depends on switching frequency of the power semiconductors. Normally, voltage or current in devices moves to discrete values, forcing the design of machines with good isolation, and sometimes load with inductances in excess of the required value. In other words, neither voltage nor current are not up to the expected level which means harmonic contamination, additional power losses, and high frequency noise that can affect the controllers. All these reasons have generated many research works on PWM modulation [1-4]. Some traditional high-frequency pulse width modulation (PWM) inverters for automotive drives can have problems associated with their high rate of change of voltage $(\mathrm{dv} / \mathrm{dt})$, which produces a common mode voltage. High frequency switching may be one of the problems to generate common mode voltage. PWM controlled inverters also require a greater amount of heat removal because of the additional switching losses [4-6]. Chain inverters solve these problems because their individual devices have a much lower $\mathrm{dv} / \mathrm{dt}$ per switching cycle. Chain link converters [5-7] work with amplitude modulation rather than pulse modulation, and this fact makes the smooth outputs of the inverter. This way of operation allows having almost sinusoidal currents and voltage waveforms, eliminating most of the undesirable harmonics. The bridges of each converter work even at a very low switching frequency, which gives the possibility to work with low speed semiconductors, and reduces switching losses [8-10]. The objective of this paper is to high light the advantages of chain link converters for various applications. Chain link converter circuit consists of four major areas - controller unit, power drive, 
power electronic converter and load. The controller unit depends mainly on the controller technique and hardware approaches. It provides control signals to the high power converter. The signal is amplified via a power drive circuit to turn on/off proper power devices of the converter. The function of the converter is to transfer and regulate the power with high efficiency from the main supply to the load. A four-stage converter using three-state power modules, which gives 81 different levels of voltage amplitude and the results are compared with conventional PWM modulators for a switching frequency of $10 \mathrm{kHz}$. All the load parameters of both types of inverters are set at the same values.

\section{Basics Of Three Level Converters}

\section{A. Basic Principle}

Fig.1 shows the basic topology of one converter used for the implementation of multi-stage converters. It is based on four switch converter, used for single phase inverters or for dual converters. These converters are able to produce three levels of voltage in the load: $+\mathrm{Vdc},-\mathrm{Vdc}$, and Zero.

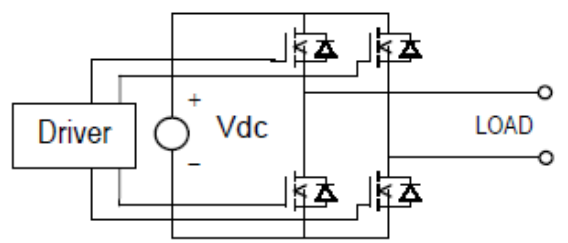

Figure 1. Three-level module for building multiconverters

\section{Chain Link Converte}

\section{Chain Link Inverter}

Chain inverters are used for a source of high power, often used in industrial applications and can use either sine or modified sine waves. Instead of using a converter to convert an AC into a DC a chain inverter which uses a series of semiconductor power converters usually two or three stages for generating higher voltage. The chain link inverter comprises number of IGBT converter links $^{6}$ connected in series to form a separate _chain' per phase as shown in figure $2 . \quad$ Each link ${ }^{6}$ consists of 3- level, full bridge VSC [11] with four IGBT-diode pairs as switches. By switching each IGBTdiode pairs -ON/OFFll once per cycle of the fundamental frequency, a 3 - level output voltage waveform is synthesized for each link. Therefore, with $\mathrm{N}$ links in series (where $\mathrm{N}$ is a positive integer), the chain link converter output voltage contains $(2 \mathrm{~N}+1)$ voltage levels that can give a good approximation to a sine wave. The total (fundamental frequency) output voltage of the CLI is thus the sum of the individual link ac voltage, and similarly for the total CLI rating. The circuit of CLI is shown in Fig2 below.

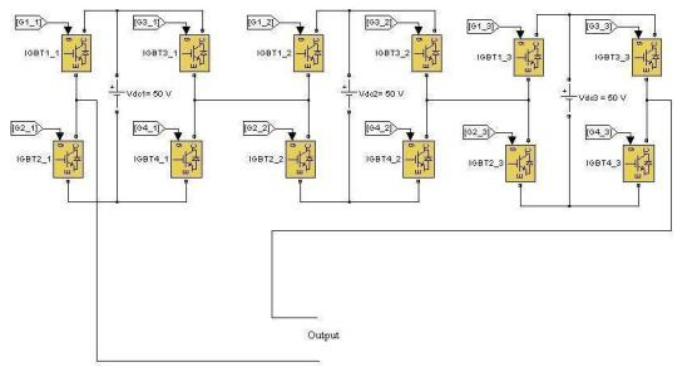

Fig 2. Circuit Diagram of CLI (Chain Link inverter)

\section{Driver Unit}

The driver unit drives the control signals to the chain link inverter and isolates the inverter control unit from power unit. It operates with the voltage range of (7-10) V dc and lower power ratings. The control unit consists of linear and digital integrated circuits. Microcomputers, microprocessors, microcontrollers and digital signal processor have made a tremendous impact in to generate gating signals. They also enable the implementation of sophisticated and complex algorithms for control and protection. In DC-AC inverter system, the power drive control unit has been upgraded continuously from complex and large current to be integrated in a small IC. For the old generation of gate drive circuits, the inverter typically use 
optocouplers with a number of discrete devices that tend to results in high component count and bigger size of board space. This power circuit interfaces the microcontroller and inverter switches.

\section{Controller Unit}

Mmicrocontrollerisa single chip controller containing a processor core,memory andprogrammableinput/outputperipherals. Program memory in the form of NOR flash or OTP ROM is also often included on chip, as well as a typically small amount of RAM. Microcontrollers are designed for embedded applications, in contrast to the microprocessors used in personal computers or other general purpose applications. It can be used to controls the operation of a system. In CLI, a good approximation of the sinusoidal voltage waveform can be produced by a set of triangular carrier signals and a sinusoidal modulating signal using a technique known as -Sinusoidal Pulse Width Modulation (SPWM)\|. For the CLI, there are two triangular carriers per link and one modulating signal for all the links. Therefore, in a CLI having $\mathrm{N}$ - links, a total of $2 \mathrm{~N}$ triangular carriers are required. The frequency of the triangular carriers $(f \mathrm{c})$ is selected to be twice the fundamental frequency $(f \mathrm{o})$ so that each IGBT-diode switches-ON/OFF\| only once per cycle of the fundamental frequency. The frequency of the modulating signal $(f \mathrm{~m})$ is chosen as the fundamental frequency. The intersection points of the triangular carrier signals and the modulating signal determine the switching instants. Fig 3 shows the SPWM [12-13] waveforms used for the chain link converter with 3-links. The upper carrier signals switch the IGBT-diode pairs G1 and G4 to contribute +Vdc to the output voltage. The lower carrier signals switch the IGBT-diode pairs G2 and G3 to contribute -Vdc. When the carrier does not intersect the modulating signal, the link is in a non contributing state

\section{Matlab Simulation Results}

The simulation of chain link inverter circuit operation with MATLAB simulation can be divided into three parts. First, is the simulation of PWM generation sub system shown in Fig 3, secondly complete circuit of three-links chain link converter circuit and the last part is the total harmonic distortion (THD). Fig 5 shows the output PWM waveforms of the PWM generation sub system. It consists of six pulses that used to trigger a three-links CLC. The first two pulses are for first link, and the second pair pulses are for second link and so on. The -ONIl period of the first link is the longest, while the -ON\| time for the second link is slightly shorter than the first link, and the last link has the shortest -ONII period. Fig 4 shows the complete simulink model of Chain Link Converter. Fig 6 shows the output voltage and current waveforms of a three- links chain link converter and fig 7 shows voltage harmonics present in the output

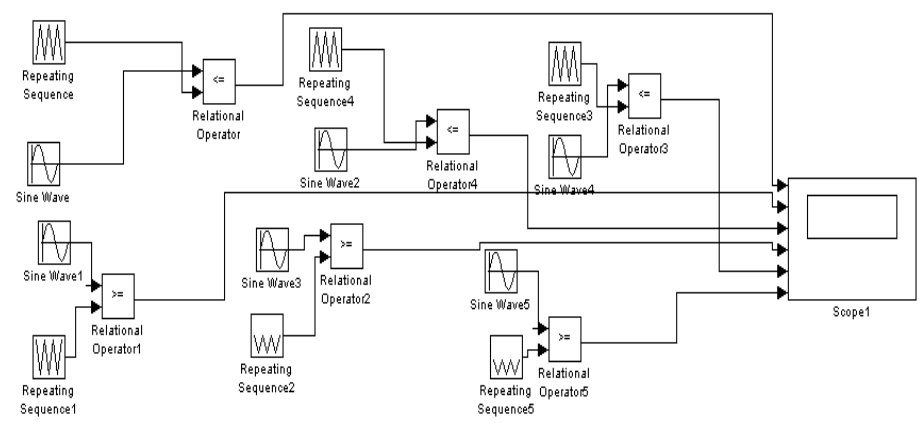

Fig 3. Subsystem for Generation of Gate Signals Using SPWM

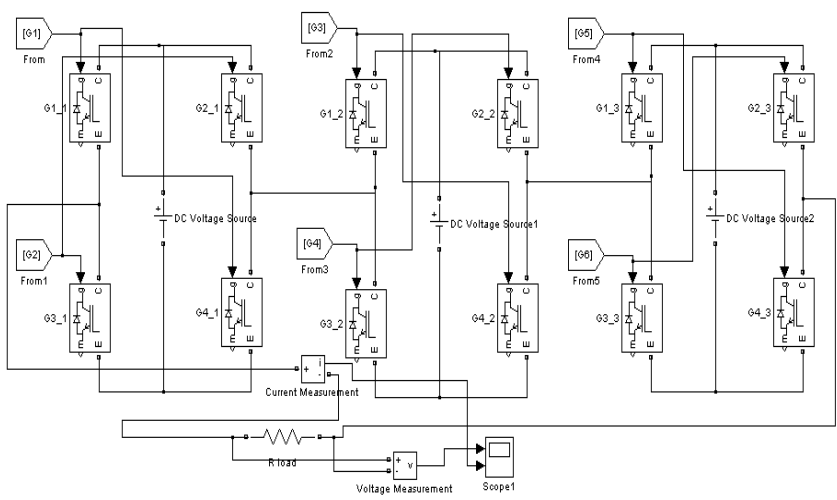

Fig 4. Simulink Model of Chain Converter 


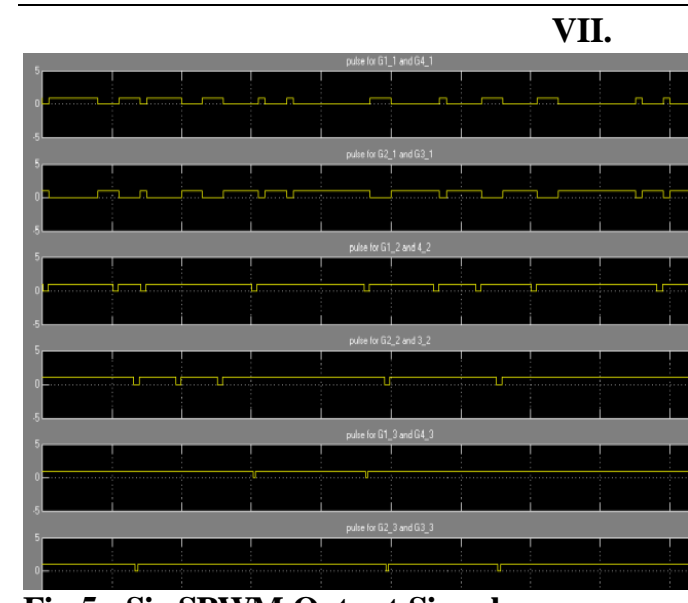

Fig 5. Six SPWM Output Signals
Matlab Graphs-

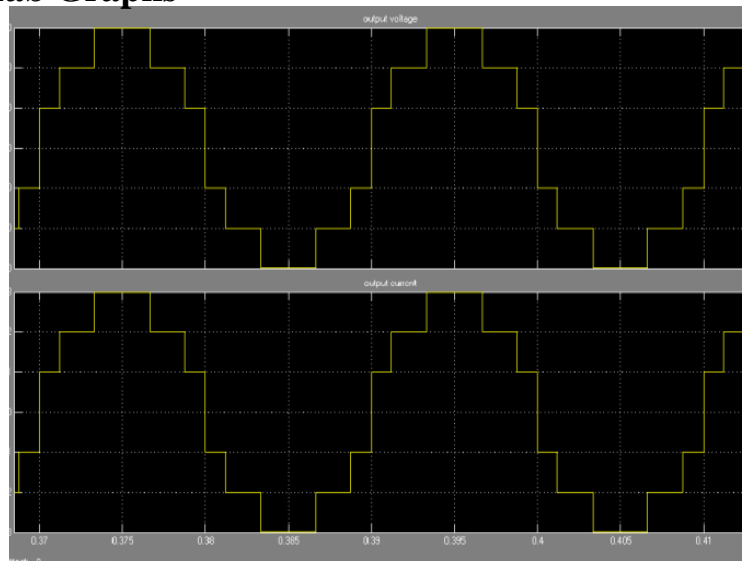

Fig 6. Output Voltage and Output Current Waveforms for Resistive load

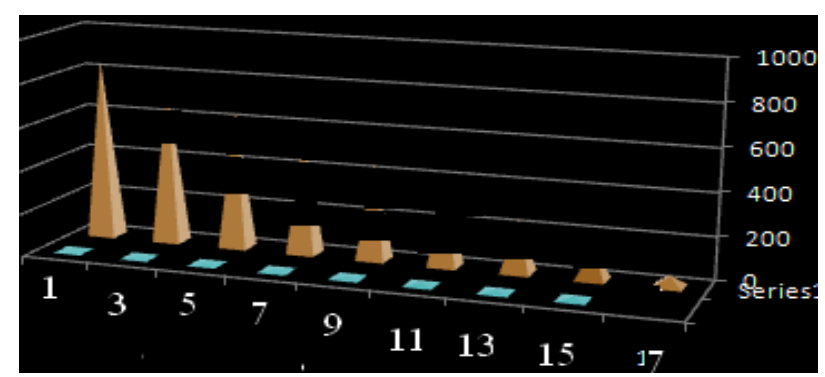

Fig 7. Output voltage harmonics

\section{Conclusion}

A chain link converter, with three series-connected links, was simulated in MATLAB. The SPWM technique has been used to drive the IGBTs of CLI, such that each IGBT turns ON/OFF once per cycle of the fundamental frequency. This can reduce the converter losses by producing a 3-level output voltage waveform per link and to synthesize the output voltage of seven level chain link converter. How ever with an inverter transfer of energy is done with the flip of one switch, where with a chain inverter requires a flip of several switches, each switch requiring a circuit. These multiple switchesand circuits usually make multilevel inverters more expensive than inverters. Unlike standard inverters, chain inverters make use of renewable energy sources. Wind, fuel cells and even photovoltaic energy can be added to a chain inverter as DC sources. These environmentally-friendly energy

sources can then be converted into AC currents. However, while chain inverters are capable of producing large amounts of energy, the amount of energy produced is dependent upon how much DC power is being used. Higher sources of DC power will provide more powerful AC power. The chain inverter's unique structure allows them to reach high voltages with low harmonics without the use of filters. The THD has been reduced in the case of 3-links chain converters. The proposed topology results in reduction of dc sources and switches number, losses, installation area and converter cost.

\section{Acknowledgement}

I am heartly greatful to all my faculties for their encouragement and support during my work on this project. My special thanks goes to Dr.B.Justus Rabi Sir for his guidance in completion of this paper. I would also like to express my gratitude towards my lecturers Mrs. K.V.Bindu and Mrs. S. Krishnaveni for their assistance in carrying Matlab Simulations.

\section{BOOKS-}

\section{References}

[1] Shukla, A., A. Ghosh, and A. Joshi, 2007. -Multilevel Converters for Unified Power Flow Controller: A Performance Based Analysisl, IEEE PowerEngineering Society GeneralMeeting 2007, Tampa, USA, 24-28 June 2007, pp. 1-8.

[2] Skvarenina, T.L., 2002. Power Electronics Handbook. USA: CRC Press,2002.

[3] Soto, D. and T.C. Green, 2002. -A Comparison of High-Power Converter Topologies for the Implementation of FACTS Controllersil, IEEE Transaction on Industrial Electronics, Volume 49, Issue 5, October 2002, pp. 1072-1080.

[4] Zambra, D.A.B., C. Rech, F.A.S. Goncalves and J.R. Pinheiro, 2008. -Power Losses Analysis and Cooling System Design of Three 
Topologies of Multilevel Invertersll, IEEE Power Electronics Specialists Conference 2008, 15-19 June 2008, pp. 4290-4295.

[5] Dubey, G.K., (1989), Power Semiconductor Controlled Drives, Prentice Hall.

[6] Rashid M.H., (2001), Power Electronics Handbook, 2nd edition, Academic Press.

\section{Proceedings Papers:}

[7] Shah N.M., Sood V.K.and Ramachandran V., (2006), Modeling of a chain link STATCOM inEMTP- RV, IEEE CCECE/CCEI, Ottawa. USA. Pp $1252-1257$.

[8] Zhong D., Tolbert, L.M. Chiasson, J.N. Hui Li, (2005), Low switching frequency active harmonic elimination in multilevel converters with unequal DC voltages, Industry Applications Conference, Fortieth IAS Annual Meetingm Conference, (1), pp 92-98.

[9] Zhong D., Leon M.T, and John N.C, (2004), Harmonic Elimination for Multilevel Converterwith Programmed PWM Method, IEEE Transactions on Industry Applications, pp 2210-2215.

[10] European Journal of Scientific esearch. http://www.eurojournals.com/ejsr.htm

[11] Rodriguez, J., J.S. Lai and F.Z. Peng, 2002. -Multilevel Inverters: A Survey of Topologies, Controls and Applicationsll, IEEE Transaction on Industrial Electronics, Volume 49, Issue 4, Augu st 2002, pp.724-738.

[12] Nguyen, T.H., P.K.W. Chan, Y. Shrivastava and S.Y.R. Hui, 2005. -A Three-Dimensional Space Vector Modulation Scheme for Three-Level Three- Wired Neutral Point Clamped Converters\|, IEEE 36th Power Electronics Specialists Conference 2005. pp. 2307-2314.

[13] Franquelo, L.G., J.Rodriguez, J.I. Leon, S. Kouro, R. Portillo, and M.A.M. Prats, 2008. -The Age of Multilevel Converters Arrives\|, IEEE Industrial Electronics Magazine, June 2008, pp.28-39. 